\title{
25 Research Soure \\ Study on Interaction Mechanism of Different Atomic Ratio of Neodymium, Arsenic and Iron
}

\author{
Juncheng Mao \\ Guizhou University \\ Run Huang \\ Guizhou University \\ Chenghui Fu \\ Guizhou University \\ Xiaodong LV \\ Chongqing University \\ Lihua $\mathrm{He}$ \\ Guizhou University \\ Jinzhun Zhang ( $\sim$ jzzhang@gzu.edu.cn ) \\ Guizhou University
}

\section{Research Article}

Keywords: neodymium, arsenic, iron, compound, heterogeneous nucleation

Posted Date: November 24th, 2020

DOI: https://doi.org/10.21203/rs.3.rs-107056/v1

License: (c) (1) This work is licensed under a Creative Commons Attribution 4.0 International License.

Read Full License

Version of Record: A version of this preprint was published at Scientific Reports on February 19th, 2021. See the published version at https://doi.org/10.1038/s41598-021-83698-9. 
1 Study on Interaction Mechanism of Different Atomic

2 Ratio of Neodymium, Arsenic and Iron

3 Juncheng Mao ${ }^{1,2}$, Run Huang ${ }^{1,2,}$, Chenghui Fu 1,2, Xiaodong Lv ${ }^{3}$, Lihua He ${ }^{1,2}$ and

4 Jinzhu Zhang ${ }^{1,2, *}$

51 School of Materials and Metallurgy, Guizhou University, Guiyang 550025, PR China

62 Guizhou Province Key Laboratory of Metallurgical Engineering and Energy Process Saving, Guiyang

$7 \quad 550025$, PR China

3 College of Materials Science and Engineering, Chongqing University, No.174 Shazheng Street, Shapingba District, Chongqin, 400044, PR China

* Correspondence: rhuang@gzu.edu.cn, jzzhang@gzu.edu.cn

Abstract: In this study, neodymium and arsenic were sealed into industrial pure iron cylinders at a temperature of $1223 \mathrm{~K}$ for $50 \mathrm{~h}$. The interaction mechanism of the Nd-Fe-As system at various atomic ratios was investigated by optical microscopy, $\mathrm{X}$-ray diffractometry, and scanning electron microscopy. Binary compounds $\mathrm{Fe}_{12} \mathrm{Ass}_{5}, \mathrm{NdAs}, \mathrm{Fe}_{2} \mathrm{As}$, and $\mathrm{Fe}_{17} \mathrm{Na}_{2}$ were the main products formed, with traces of $\mathrm{NdFeAs}$ compounds. In addition, at high temperatures, As content affected the diffusion of $\mathrm{Fe}$ atoms; the diffusion of $\mathrm{Fe}$ increased with an increase in the atomic ratio. Furthermore, the diffusion ability of $\mathrm{Nd}$ was weaker than that of As. The major diffusion mechanism of Nd was through the Fe atomic vacancy mechanism. As mainly bind to Fe to form Fe and As compounds. The formation of ternary compounds was confirmed by laboratory experiments and mismatch calculations.

Keywords: neodymium; arsenic; iron; compound; heterogeneous nucleation

\section{Introduction}

Rare earth elements (including 15 lanthanide elements, scandium, and yttrium ${ }^{1-3}$ in the third subgroup of the periodic table) are widely used for the purification, metamorphosis, and alloying of metals $^{4-5}$. The unsaturated outer electronic layer of rare earth elements is considered as a special form of new materials, which can burst out a variety of electron energy levels and exhibit high "vitality" in its external performance. In addition, rare earth elements are regarded as a treasure of new materials because of its unique electrical and magnetic properties. Arsenic, as a deleterious element commonly occurring in steel, leads to the segregation of As, grain boundary segregation, and oxidation during solidification, which deteriorate the thermoplastic, tempering brittleness, hot workability, and mechanical properties of steel ${ }^{6}$. Rare earth elements can react with As (with a low melting point) to form compounds with high melting point because of their active chemical properties, thus improving the thermoplastic and mechanical properties of steel.

According to the iron-neodymium (Fe-Nd) binary phase diagram ${ }^{[7]}$, the stable compounds that can be formed between $\mathrm{Fe}$ and $\mathrm{Nd}$ include $\mathrm{Fe}_{17} \mathrm{Nd}_{2}$ and $\mathrm{Fe}_{2} \mathrm{Nd}$, and according to the Fe-As binary phase diagram, the stable compounds that can be formed between $\mathrm{Fe}$ and As include $\mathrm{Fe}_{2} \mathrm{As}$, $\mathrm{Fe}_{3} \mathrm{As} 2$, $\mathrm{FeAs}$, and $\mathrm{FeAs}_{2}^{8}$. Generally, the maximum solubility of As in Fe is approximately $10 \%$ at $1113 \mathrm{~K}^{9}$. However, the solubility decreases with a decrease in temperature and reduces to below $5 \%$ at room temperature ${ }^{10-12}$. For Re-Fe-As ternary system, the main products including $\mathrm{REFe}_{4} \mathrm{As} 12, \mathrm{REFe}_{2} \mathrm{As} 2$ ( $\mathrm{RE}=\mathrm{La}, \mathrm{Nd}, \mathrm{Sm}$ ) have been widely reported. Different atomic ratios of cerium (lanthanum), Fe, and As form the ternary compound RE12Fe57.5As41 (RE=La, Ce) and FeAs at $1173 \mathrm{~K}^{13-14}$, whereas the Re-Fe-As ternary system forms $\mathrm{La}_{10} \mathrm{Fe}_{50} \mathrm{As}_{40}{ }^{15}$ at $1223 \mathrm{~K}$. In recent years, one of products of RE-Fe-As ternary system named $\mathrm{EuFe}_{2} \mathrm{As}_{2}{ }^{16-20}$ has attracted significant attention. $\mathrm{Xie}^{21}$ and $\mathrm{Fu}^{22}$ investigated the interaction of Nd-Fe-As system at high temperatures and found that the formation of the ternary compound NdFeAs depends on the formation of NdAs and FeAss. 
Therefore, in this study, a certain quality of $\mathrm{Nd}$ and As were sealed in a cylinder block, which was specially processed using industrial pure Fe by melting, infiltration, and diffusion. The interaction between $\mathrm{Nd}, \mathrm{Fe}$, and $\mathrm{As}$ at high temperature and the mechanism for the generation of ternary compounds was investigated using metallographic microscope, scanning electron microscope (SEM), and X-ray diffraction (XRD). The generation of ternary compounds was partly confirmed by calculations and laboratory experiments.

\section{Materials and Methods}

Figure 1 shows the barrel-shaped cylinder composed of industrial pure $\mathrm{Fe}$; its principal chemical composition (mass fraction) is as follows: $0.002 \% \mathrm{C}, 0.02 \% \mathrm{Mn}, 0.006 \% \mathrm{P}, 0.004 \% \mathrm{~S}, 0.005 \%$ $\mathrm{Al}$, and $99.95 \% \mathrm{Fe}$. Nd metal block (purity $>99.9 \%$ ) and As block (diameter $<1 \mathrm{~mm}$, see Table 1) were filled into the industrial pure Fe cylinder block at various atomic ratios (1:1,1:2,1:3), the screw plug was welded by arc welding, and a high temperature sealant was applied to the weld to ensure it is properly sealed. Subsequently, the industrial pure Fe cylinder block was placed in a closed tube vacuum furnace and heated under high purity argon SRJK-2-9 atmosphere. The experimental heating process is shown in Table 2, and it depended on the vapor pressure of As. After the heating process, the temperature of the furnace was reduced to room temperature $\left(30^{\circ} \mathrm{C}\right)$. Subsequently, argon flow into the furnace was stopped and the cylinder sample was taken out. Then, the outer side of the cylinder block was marked away from its bottom (at a distance of $16 \mathrm{~mm}$ ); in the radial direction, it was sawed and divided into two parts, one of which was processed into metallographic samples and the other part was used for XRD analysis. The phase composition of the samples was analyzed using a PHILIPS X'-Pert PRO diffractometer, and the test parameters are as follows: Copper target, $\lambda=0.154056 \mathrm{~nm}, 40 \mathrm{kV}$ operating voltage, $2 \%$ min scanning speed.
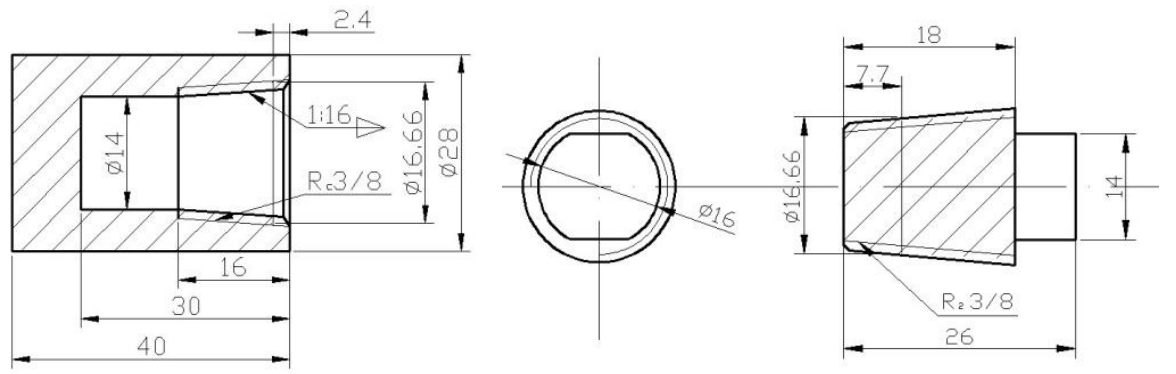

Figure 1. Schematic of the barrel-shaped cylinder and the screw plug.

Table 1. Masses of $\mathrm{Nd}$ and $\mathrm{As}$ and the atomic ratio of $\mathrm{Nd}$ :As for sample preparation.

\begin{tabular}{|c|c|c|c|c|c|}
\hline Sample & Atomic ratio & $\mathbf{N d} / \mathbf{g}$ & $\mathbf{A s} / \mathbf{g}$ & $\mathbf{T} / \mathbf{K}$ & $\mathbf{t} / \mathbf{h}$ \\
\hline $1 \#$ & $1: 1$ & 6.5814 & 3.4185 & 1223 & 50 \\
\hline $2 \#$ & $1: 2$ & 4.9014 & 5.0985 & 1223 & 50 \\
\hline $3 \#$ & $1: 3$ & 3.9089 & 6.0911 & 1223 & 50 \\
\hline
\end{tabular}

Table 2. Experimental heating process.

\begin{tabular}{|c|}
\hline \multicolumn{2}{|c|}{ Experimental heating process } \\
\hline Room temperature $\stackrel{2 \mathrm{~h}}{\longrightarrow} 773 \mathrm{~K} \stackrel{10 \mathrm{~K} / 10 \mathrm{~min}}{\longrightarrow} 923 \mathrm{~K} \stackrel{10 \mathrm{~K} / 20 \mathrm{~min}}{\longrightarrow} 983 \mathrm{~K} \stackrel{10 \mathrm{~K} / 30 \mathrm{~min}}{\longrightarrow}$ \\
$1023 \mathrm{~K} \stackrel{10 \mathrm{~K} / \mathrm{h}}{\longrightarrow} 1073 \mathrm{~K} \stackrel{10 \mathrm{~K} / 2 \mathrm{~h}}{\longrightarrow} 1123 \mathrm{~K} \stackrel{10 \mathrm{~K} / 5 \mathrm{~h}}{\longrightarrow} 1173 \mathrm{~K} \stackrel{10 \mathrm{~K} / 6 \mathrm{~h}}{\longrightarrow} 1223 \mathrm{~K}(50 \mathrm{~h})$ \\
\hline
\end{tabular}

\section{Results}

Metallographic Analysis 
Figure 2 shows the metallographic images of the samples at various atomic ratios under an optical microscope. At a constant heating temperature and holding time, three types of contrast (grayish, gray, and black) were observed at different atomic ratios. The grayish part indicates the collective part of the cylinder, most of which was the industrial pure $\mathrm{Fe}$, the gray part has a higher proportion of As, and the black part has a higher proportion of $\mathrm{Nd}$. Figure 2(a) shows the neighboring area of the cylinder block, which indicates that the entire area was divided into two different parts: the cylinder matrix on the left and the core component on the right. In addition, inhomogeneous granular structures were formed at all atomic ratios (the right area), and they contained the same white liner as the cylinder matrix. With an increase in the atomic ratios, the symmetry of the entire granular structure increased and then decreased. In addition, with an increase in the diffusion of the grayish area, the diffusion moved farther away from the edge, which consequently reduced the diffusion. Particularly, with a decrease in the distance between the gray area and the edge of the boundary, the proportion of the gray area reduced. At high temperatures, the Fe atom diffused into the core area of the sample, while the $\mathrm{Nd}$ atom diffused into the matrix area, and the Fe and As atoms diffused together, and consequently, Fe atoms gradually formed a circular structure.

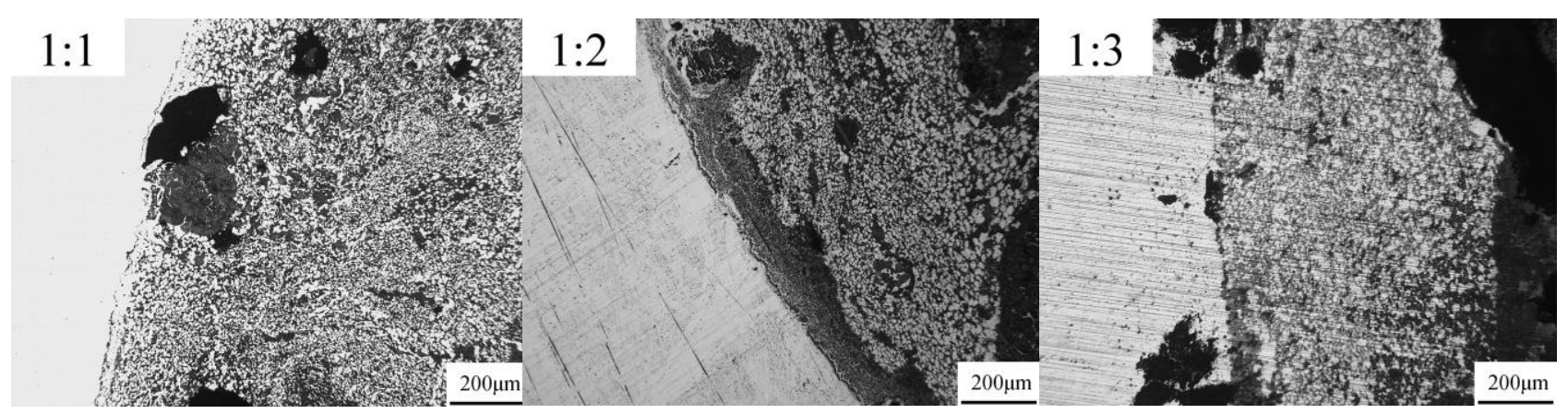

(a)

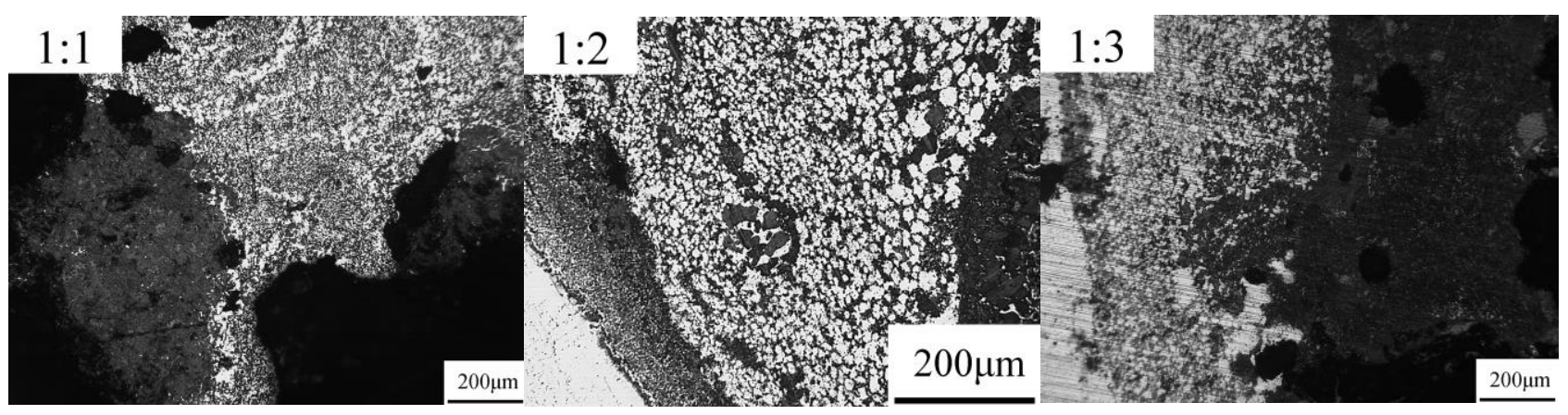

(b)

Figure 2. Metallographic pictures of atoms at different atomic ratio, (a) Pictures of the cylinder block's neighboring area, (b) Pictures around its core area.

\section{Phase Analysis}

For the phase analysis, the sample from the core area was ground in a mortar into a powder. Subsequently, the phase of the samples was characterized by XRD analysis, as shown in Figure 3. The main diffraction peaks observed in the XRD spectra could be attributed to the formation of five types of compounds $\left(\mathrm{Fe}_{12} \mathrm{As} 5, \mathrm{Fe}_{2} \mathrm{As}, \mathrm{NdAs}, \mathrm{Fe}_{17} \mathrm{Nd}_{2}\right.$, and $\alpha$-Fe) in the ternary system of the high-temperature fusion samples. When the atomic ratio of $\mathrm{Nd}$ and $\mathrm{As}$ was 1:1 and 1:2, the intensity of the diffraction peaks was stable. During the experiment, As sublimed at high temperatures, while the highly reactive $\mathrm{Nd}$ reacted with As. Consequently, the amount of compounds (NdAs) increased. 


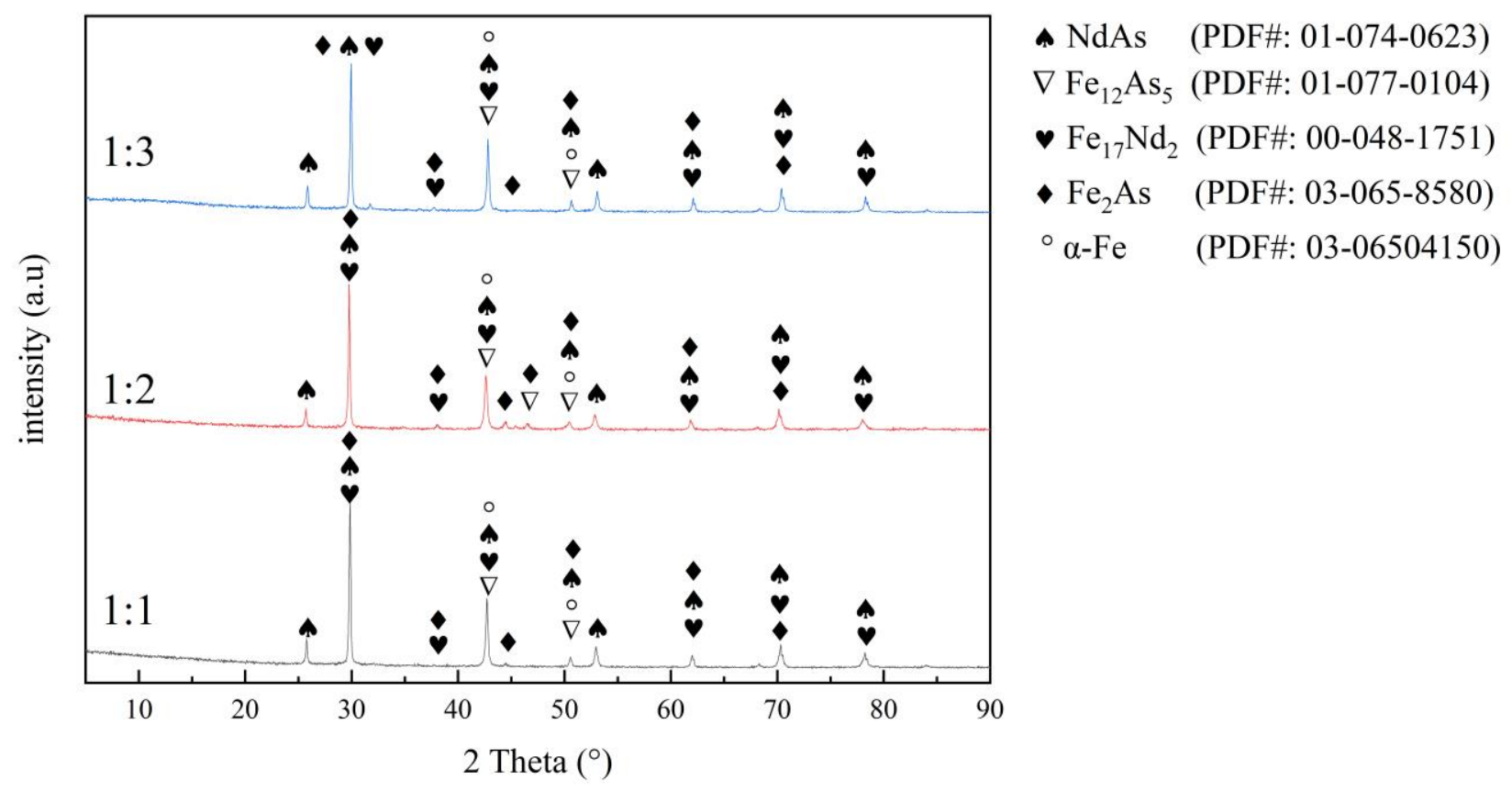

Figure 3. X-ray diffraction spectra of the samples at different atomic ratio. literature. However, the energy dispersive spectroscopy (EDS) analysis suggests the formation of the ternary compounds (NdFeAs).

SEM analysis was carried out on the reduced sample, and EDS analysis was employed to analyze the image at different contrasts. As shown in Figure 4, the samples are mainly distributed in four types of contrast phase (black, dark gray, light gray, and white), which are identified by A, B, C, and D, and each contrast phase tissue was investigated using EDS analysis; the results are shown in Table 3. The microstructure of the black, dark gray, and light gray contrast had an irregular shape. In addition, the gray and light gray components were mainly composed of $\mathrm{Nd}$ and As, combined with the XRD spectra of $\mathrm{Nd}$ and As, this result indicates that the contrast phase structure was a NdAs crystal structure, whereas the black contrast phase structure was mostly saturated As $\alpha$-Fe solid solution.

As discussed above, the products of $\mathrm{Nd}$ and As at different atomic ratios $(1: 1,1: 2,1: 3)$ contained $\mathrm{Fe}_{12} \mathrm{As} 5, \mathrm{Fe}_{2} \mathrm{As}$, NdAs, and $\mathrm{Fe}_{17} \mathrm{Nd}_{2}$ in all the ternary systems. However, the amount of different phases changes with an increase in the atomic ratios, and the various contrast phase structures show

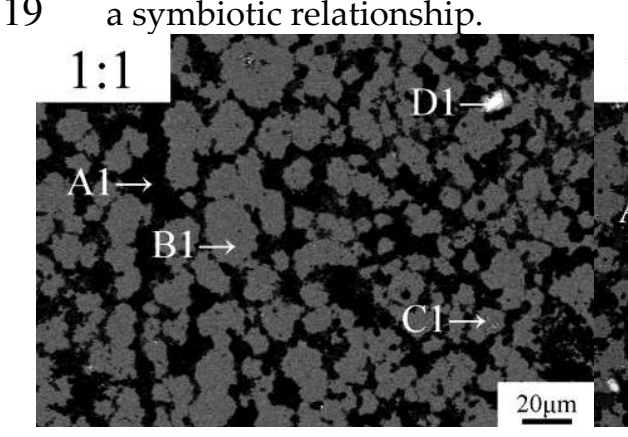

(a)

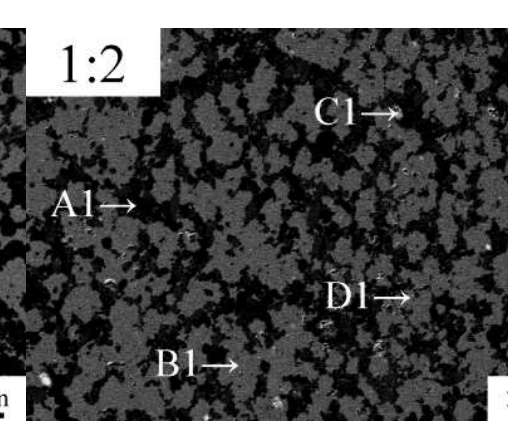

(b)

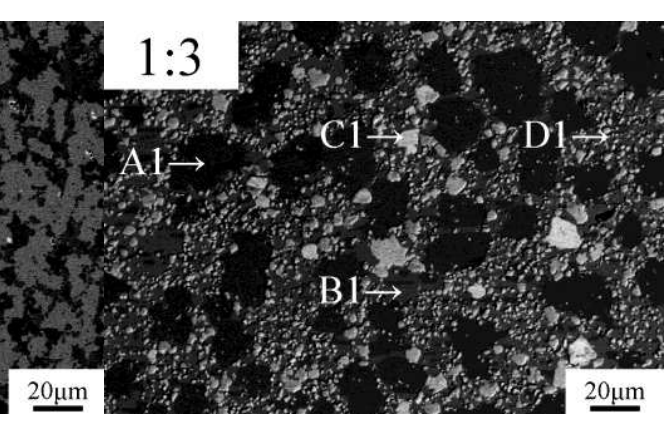

(c)

Figure 4. Backscattered electron maps of the sample at various atomic ratios (a) 1:1, (b) 1:2, (c) 1:3. 
Table 3. EDS analysis results of different atomic ratio samples (at $/ \%$ ).

\begin{tabular}{|c|c|c|c|c|c|c|c|c|c|c|c|}
\hline Positions & Nd & As & Fe & Positions & Nd & As & Fe & Positions & Nd & As & Fe \\
\hline A1 & 45.39 & 48.93 & 5.69 & A1 & 44.32 & 43.34 & 12.34 & A1 & 0.25 & 9.07 & 90.68 \\
\hline B1 & 35.14 & 42.24 & 22.63 & B1 & 39.98 & 39.33 & 20.69 & B1 & 39.39 & 42.34 & 18.27 \\
\hline C1 & 21.11 & 21.89 & 57.00 & C1 & 20.79 & 27.75 & 51.46 & C1 & 50.79 & 46.96 & 2.24 \\
\hline D1 & 2.27 & 11.21 & 86.52 & D1 & 8.50 & 18.87 & 72.63 & D1 & 0.74 & 8.55 & 90.72 \\
\hline
\end{tabular}

Diffusion analysis of samples

Figure 5 shows the line-scanning atlas analysis of the transition areas of $\mathrm{Nd}$ and $\mathrm{As}$ at different 123 atomic ratios. According to the graph, the three elements $(\mathrm{Nd}, \mathrm{Fe}, \mathrm{As})$ were in a continuous 124 distribution in a banded gradient. In addition, the amount of $\mathrm{Nd}$ in the white contrast region was 125 significantly higher than that in other regions. Furthermore, the amount of Fe in the black contrast 126 region was the highest, and As existed in all the contrast phases.

127 During the experiment, Fe diffused into the cylinder block, whereas the diffusion activation 128 energy of As was lower than that of $\mathrm{Fe}^{23}$. In addition, As diffused via the formation of $\mathrm{Fe}$ and As 129 compounds, and $\mathrm{Nd}$ diffused via its vacancy mechanism and the formation of the Fe and As 130 compounds. Because the chemical potential of $\mathrm{Nd}$ increased with an increase in its content, and the 131 solubility of As was maintained at $10 \%$ during experimental temperature, vacancies were produced 132 during the sublimation process. The interaction between As and Nd produced NdAs compounds, 133 and the remaining $\mathrm{Nd}$ and $\mathrm{Fe}$ formed $\mathrm{Fe}_{17} \mathrm{Nd}_{2}$ compounds to fill the vacancies. In addition, Fe 134 vacancies were formed by thermal vibration; consequently, these vacancies provided a condition for 135 the diffusion of $\mathrm{Nd}^{24}$. Furthermore, the grain size gradually decreased, thus increasing the grain 136 boundary area. Simultaneously, the grain boundary vacancies increased accordingly. The combined 137 effect of the generated vacancies, the Nd-generated solute-vacancy compounds, and the 138 enhancement of the thermal diffusion rate leads to the segregation of $\mathrm{Nd}$ at the grain boundary.

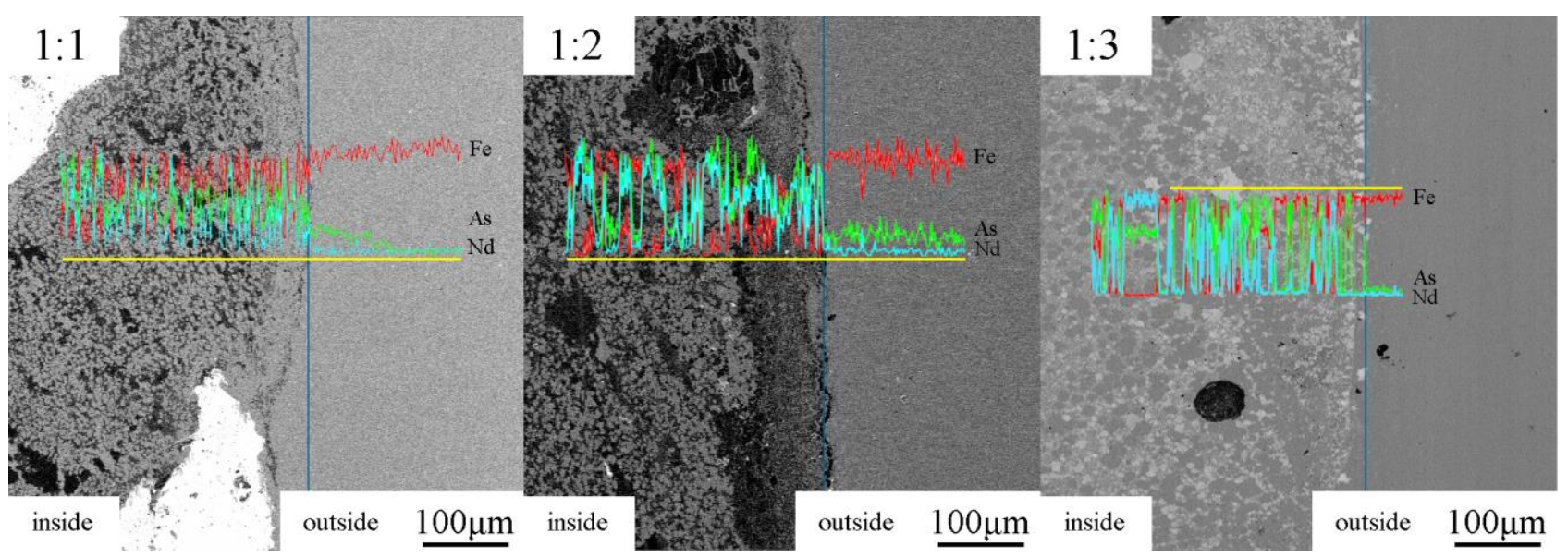

Figure 5. Sweep spectrum of the edge line of the cylinder samples at different atomic ratio. 
According to the planar mismatch theory, the calculation result of the mismatch of two planes 141 should be less than $6 \%$ to achieve good heterogeneous nucleation; heterogeneous nucleation is 142 expected to occur if the mismatch is greater than $12 \%$. The planar mismatch can be calculated using 143 Equation $(1)^{25}$.

$$
\delta_{(h k l)_{n}}^{(h k l)_{s}}=\frac{1}{3} \sum_{i=1}^{3}\left[\frac{\left|d_{[u v w]_{s}}^{i} \cos \theta-d_{[u v w]_{n}}^{i}\right|}{d_{[u v w]_{n}}^{i}}\right] \times 100
$$

144 145 146

where $\delta$ is the average of the three mismatches between the $(h k l)_{s}$ and $(h k l)_{n}$ planes; $d_{[u v w]_{s}}$ and $d_{[u v w]_{n}}$ is the interatomic spacing along $[u v w]_{s}$, and $[u v w]_{n}$ respectively; and $\theta$ is the angle between two corresponding direction.

The atom matching diagram of the surface between the $\mathrm{Fe}_{12} \mathrm{As}_{5}$ (0001) and $\mathrm{NdAs}$ (111) planes is illustrated in Figure 6 and Figure 7. The former is indicated by yellow circles and the latter is indicated by green circles. The crystal parameters involved in the calculations are listed in Table $4{ }^{26}$, and the specific calculation data are shown in Table 5. The calculation results of the two mismatched planes was $17.86 \%$, indicating that $\mathrm{Fe}_{12} \mathrm{As} 5$ cannot be used as the effective heterogeneous nucleation core in the formation $\mathrm{NdAs}$.

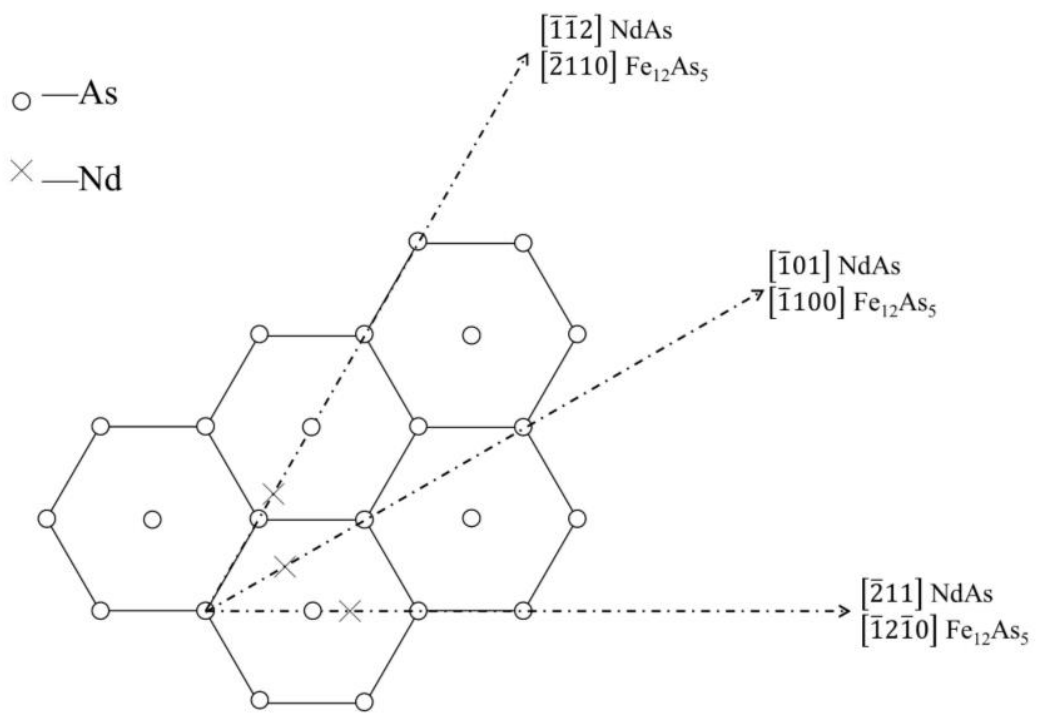

Figure 6. Crystallographic relationships of the Fe12Ass (0001) and NdAs (111) planes.

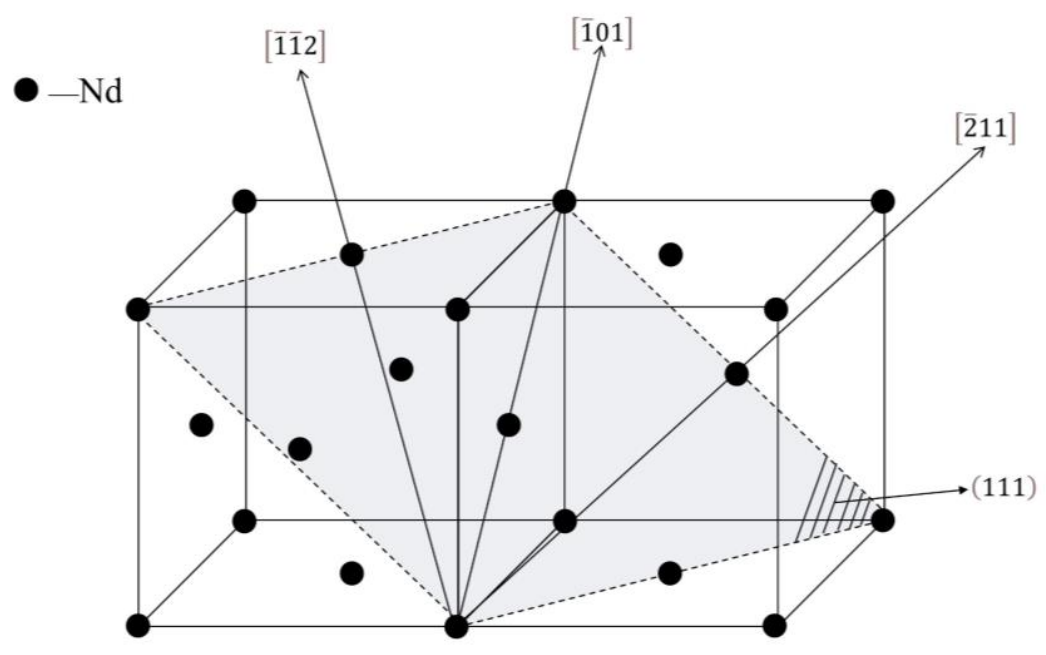


The calculation results of the mismatch are listed in the table 6 . The mismatch between $\mathrm{Fe}_{2} \mathrm{As}$ and $\mathrm{NdFeAs}$ was $8.33 \%$, indicating the high probability for $\mathrm{Fe}_{2} \mathrm{As}$ to effectively act as the heterogeneous nucleation cores for the formation of ternary NdFeAs compound.

160

Table 4. Crystallographic parameters of possible compounds of $\mathrm{Nd}$ and As in steel.

\begin{tabular}{|c|c|c|c|c|}
\hline \multirow{2}{*}{ Compounds } & \multirow{2}{*}{ Crystal System } & \multicolumn{3}{|c|}{ Lattice Parameters $\left(\mathbf{2 5}^{\circ} \mathbf{C}, \mathbf{n m}\right)$} \\
\cline { 3 - 5 } & & $a_{0}$ & $b_{0}$ & $c_{0}$ \\
\hline $\mathrm{Fe}_{12} \mathrm{As} 5$ & hexagonal & 0.6786 & - & $1.6301-$ \\
\hline $\mathrm{NdAs}$ & cubic & 0.5987 & - & - \\
\hline $\mathrm{Fe}_{2} \mathrm{As}$ & tetragonal & 0.3632 & - & 0.5981 \\
\hline $\mathrm{Fe}_{17 \mathrm{Nd}}$ & hexagonal & 0.8574 & - & 1.2464 \\
\hline $\mathrm{NdFeAs}$ & tetragonal & 0.39655 & - & 0.8575 \\
\hline
\end{tabular}

161

Table 5. Calculation details of the lattice between $\mathrm{Fe}_{12} \mathrm{As} 5$ and $\mathrm{NdAs}$ compounds.

\begin{tabular}{|c|c|c|c|}
\hline Interface & \multicolumn{3}{|c|}{$(0001) \mathrm{Fe}_{12} \mathrm{As}_{5} / /(111) \mathrm{NdAs}$} \\
\hline$(h k l)_{s}$ & {$[\overline{1} 2 \overline{1} 0]$} & {$[\overline{1} 100]$} & {$[\overline{2} 110]$} \\
\hline$(h k l)_{n}$ & {$[\overline{2} 11]$} & {$[\overline{1} 01]$} & {$[\overline{1} \overline{1} 2]$} \\
\hline$d[h k l]_{s}$ & 0.6786 & 1.1745 & 0.6786 \\
\hline$d[h k l]_{n}$ & 0.7331 & 0.4233 & 0.7331 \\
\hline$\theta$ & 0 & 0 & 0.6786 \\
\hline$d[h k l]_{s} \cdot \cos \theta$ & 0.6786 & 1.1745 & 0 \\
\hline$\delta(\%)$ & \multicolumn{3}{|c}{} \\
\hline
\end{tabular}

162

Table 6. Calculated planar lattice misfits among crystal faces of Nd-Fe-As inclusions.

\begin{tabular}{|c|c|c|}
\hline Interface & $\delta(\%)$ & Effectiveness \\
\hline$(0001) \mathrm{Fe}_{12} \mathrm{As}_{5} / /(111) \mathrm{NdAs}$ & 64.11 & Least Effective \\
\hline$(0001) \mathrm{Fe}_{12} \mathrm{As}_{5} / /(0001) \mathrm{Fe}_{17} \mathrm{Nd}_{2}$ & 48.82 & Least Effective \\
\hline$(0001) \mathrm{Fe}_{12} \mathrm{As}_{5} / /(112.162) \mathrm{NdFeAs}$ & 19.95 & Least Effective \\
\hline$(001) \mathrm{NdAs} / /(001.647) \mathrm{Fe}_{2} \mathrm{As}$ & 22.96 & Least Effective \\
\hline$(111) \mathrm{NdAs} / /(0001) \mathrm{Fe}_{17} \mathrm{Nd} 2$ & 109.04 & Least Effective \\
\hline$(001) \mathrm{NdAs} / /(002.162) \mathrm{NdFeAs}$ & 28.38 & Least Effective \\
\hline$(111.647) \mathrm{Fe}_{2} \mathrm{As} / /(0001) \mathrm{Fe}_{17} \mathrm{Nd} 2$ & 37.21 & Least Effective \\
\hline$(001.647) \mathrm{Fe}_{2} \mathrm{As} / /(002.162) \mathrm{NdFeAs}$ & 8.33 & Very Effective \\
\cline { 2 - 3 }$(0001) \mathrm{Fe}_{17} \mathrm{Nd}_{2} / /(112.162) \mathrm{NdFeAs}$ & 18.36 & Least Effective \\
\hline
\end{tabular}

\section{Conclusions}

(1) When the atomic ratios of $\mathrm{Nd}$ and arsenic were between 1:1-1:3 at a maximum temperature of $1223 \mathrm{~K}$ for $50 \mathrm{~h}, \mathrm{Fe}_{12} \mathrm{As} 5, \mathrm{Fe}_{2} \mathrm{As}, \mathrm{NdAs}$, and $\mathrm{Fe}_{17} \mathrm{Nd}_{2}$ were formed. In addition, with an increase in the atomic ratios of $\mathrm{Nd}$ and $\mathrm{As}$, the formation of the $\mathrm{NdAs}$ compounds decreased and the formation of $\mathrm{Fe}_{2} \mathrm{As}$ compounds increased ( $\mathrm{Fe}_{2} \mathrm{As}$ was generated during the diffusion of As toward the cylinder block).

(2) In the ternary system (Nd-Fe-As), the diffusion of Fe was dependent on the amount of As. In addition, the Fe atom diffused toward the core of the cylinder block, and its amount decreased with 
171 increase in the depth of its diffusion. Furthermore, with an increase in the proportion of $\mathrm{Nd}$ and As, 172 the diffusion of As into the external matrix of the cylinder increased.

(3) The EDS spectra suggest the formation of ternary compounds (NdFeAs), and the mismatch calculation indicated that the $\mathrm{Fe}_{2} \mathrm{As}$ can act as effective heterogeneous nucleation cores for the formation of ternary compounds (NdFeAs).

\section{References}

1. Zhang, F., Li, Y.; Li, X. Current status of rare-earth resources development and utilization at home and abroad and suggestions for rare-earth management in China. Modern Mining. 12, 11-14.

https://dx.doi.org/10.3969/j.issn.1674-6082.2018.12.003 (2007).

2. Dutta, T., Kim, K. H., Uchimiya, M., Kwon, E. E., Jeon, B. H. \& Deep, A. et al. Global demand for rare earth resources and strategies for green mining. Environmental Research. 150, 182-190.

https://doi.org/10.1016/j.envres.2016.05.052 (2016)

3. Zhang, Y., Liu, C. S., Gao, L. F., Zhang, Z. G. \& Zhang, P. Marine authigenic deposits mineral-new fields for the development for the development of rare-earth resources. Advanced Materials Research. 291-294, 1748-1751. https://doi.org/10.4028/www.scientific.net/AMR.291-294.1748 (2011).

4. Li, W. C., Lin, Q., Ye, W. \& Zhang, C. Y. Kinetics of rare-earth effect on the low carbon steel containing arsenic. Journal of Beijing University of Iron and Steel Technology. 2, 61-67. https://dx.doi.org/10.13374/j.issn1001-053x.1983.02.025 (1983).

5. Du, T. Physical-chemistry effect of rare-earth elements on metallic material. Act Metall Sin. 33, 69-77. https://www.ams.org.cn/EN/Y1997/V33/I1/69 (1997).

6. Cheng, H. J., Wang, F. M., Li, C. R., Tan, Y. P. \& Wang, J. J. Effect of arsenic on microstructure and mechanical properties of 45 steel. Heat Treatment of Metals 35, 33-38. (2010).

7. Zhang, F. Z. The Prospect of the Application of Rare-earth in Iron and Steel from the Phase Diagram of Rare-earth. Iron Steel. 8, 66-75. (1986)

8. Brandes, E. A. \& Brook. G. B. Smithells Metals Reference Book, Butterworth-Heinemann. (1983).

9. Yin, G. The distribution of arsenic in steel. Gangtie. 16, 20-28. https://doi.org/10.13228/j.boyuan.issn0449-749x.1981.02.004 (1981).

10. Duan, S., Chen, X., Yang, B., Liu, D. \& Dai, Y. Ab-Initio Molecular Dynamics Simulation of Thermal Decomposition of Arsenic-Iron Compounds in Vacuum. Chin. J. Vac. Sci. Technol. 34, 1128-1134. https://doi.org/10.13922/j.cnki.cjovst.2014.10.23 (2014).

11. Hu, Q. Q., Zhou, J., Zhang, X. Y., Yan, Z. \& Yang, Y. T. Comparison of As(V)Removal by Three Different Types of Ferric Iron Adsorbents. Water Purif. Technol. 33, 71-74.

https://doi.org/10.15890/j.cnki.jsjs.2014.06.013 (2014).

12. Todorov, I., Chuang, D., Malliakas, C., Li, Q., Bakas, T. \& Douvalis, A. et al. CaFe4Ass: A metallic iron arsenide with anisotropic magnetic and charge-transport properties. Journal of the American Chemical Society. 131, 5405. https://doi.org/10.1021/ja900534h (2009).

13. Stoyko, S. S., Blanchard, P. E. R \& Mar, A. Ternary rare-earth iron arsenide RE12Fe57.5As41(RE=La, Ce). Inorganic Chemistry. 49, 2325-2333. https://doi.org/10.1021/ic902231b (2010).

14. Zhang, J. Z. \& Dou, S. T. Study on Interaction between Cerium and Arsenic. Advanced Materials Research. 194, 1231-1234. https://doi.org/10.4028/www.scientific.net/AMR.194-196.1231 (2011).

15. Liu, X.; Zhang, J.; Zhu, S. Microstructure and compound Developed from La-As-Fe System at $1223 \mathrm{~K}$. Advanced Materials Research. 702, 145-148. https://doi.org/10.4028/www.scientific.net/AMR.702.145 (2013).

16. Sklyarova, A., Tewari, G. C., J, Lindén., Mustonen, O., Rautama, E. L. \& Karppinen, M. Mössbauer study of hyperfine interactions in $\mathrm{EuFe}_{2}\left(\mathrm{As}_{1-\mathrm{x}} \mathrm{P}_{\mathrm{x}}\right)_{2}$ and $\mathrm{BaFe}_{2}\left(\mathrm{As}_{1-\mathrm{x}} \mathrm{P}_{\mathrm{x}}\right)_{2}$. Journal of Magnetism and Magnetic Materials. 378, 327-332. https://dx.doi.org/10.1016/j.jmmm.2014.11.054 (2015).

17. Munevar, J., Micklitz, H., Alzamora, M., Argüello, C., Goko, T. \& Ning, F. L. et al. Magnetism in superconducting EuFe2As1.4 $\mathrm{P}_{0.6}$ single crystals studied by local probes. Solid State Communications. 187, 18-22. https://doi.org/10.1016/j.ssc.2014.02.001 (2014).

18. Wu, T., Wu, G., Chen, H., Xie, Y. L., Liu, R. H. \& Wang, X. F. et al. Magnetic phase diagram of Eu1-x LaxFe2As2 single crystals. Journal of Magnetism and Magnetic Materials. 321, 3870-3874. https://dx.doi.org/10.1016/j.jmmm.2009.07.043 (2009). 
19. Terashima, T., Suzuki, H. S., Tomita, M., Kimata, M., Satsukawa, H. \& Harada, A. et al. Pressure-induced antiferromagnetic bulk superconductor EuFe2As2. Physica C Superconductivity. 470, S443-S444.

https://doi.org/10.1016/j.physc.2009.10.064 (2010).

20. Drief, F., Zaoui, A., Kacimi, S. \& Merabet, B. Ab-initio investigation of the electronic structure in the superconducting $\mathrm{EuFe}_{2}\left(\mathrm{Ass}_{-\mathrm{x}} \mathrm{P} \times\right)_{2}$. Physica C: Superconductivity and its Applications. 512, $22-27$. https://doi.org/10.1016/j.physc.2015.02.045 (2015)

21. Xie, W. H., Huang, R., Zhang, J. Z., Li, W., Yang, Y. Study on the interaction of rare earth element neodymium, iron and arsenic at 1173 K. Journal of Function Materials. 49, 1134-1138. (2018).

22. Fu, C. H., Huang, R., Xie, W. H., Luo, J. X. \& Zhang, J. Z. Study on High-Temperature Interaction Mechanism of Nd-Fe-As System. Materials. 12, 3060-. https://doi.org/10.3390/ma12193060 (2019).

23. Boi, B. I. \& Lui, R. J. Diffusion in iron-arsenic alloys. Journal of Materials Science. 11, 887-891. https://doi.org/10.1007/bf00542306 (1976).

24. Li, Y. L, Huang, R.; Yang, Y., Luo, J. X., Fu, C. H. \& Zhang, J. Z. High-temperature interaction of Ce-Fe-As ternary system. Materials Research Express. 6. https://doi.org/10.1088/2053-1591/ab1198 (2019).

25. Bramfitt, B.L. The effect of carbide and nitride additions on the heterogeneous nucleation behavior of liquid iron. Metallurgical Transactions. 1, 1987-1995. https://doi.org/10.1007/BF02642799 (1970).

26. Villars, P. Pauling file. In Inorganic Solid Phases, SpringerMaterials (Online Database); Springer: Heidelberg, Germany, (2012).

\section{Acknowledgements}

This research was funded by the Nation Natural Science Foundation of China (Grant No. 51664003 and 52064010).

\section{Author Contributions}

R.H. conceived and designed the experiment; C.F., L.X., and L.H. contributed to retrieve documents; J.M. collected the data and made the graph; J.M. analyzed the data and wrote the paper. This article was checked and revised by J.Z. All authors reviewed the manuscript.

\section{Competing interests}

248 The authors declare no competing interests.

\section{Additional information}

Correspondence and requests for materials should be addressed to R.H. or J.Z

Reprints and permissions information is available at www.nature.com/reprints.

Publisher's note Springer Nature remains neutral with regard to jurisdictional claims in published maps and institutional affiliations. 


\section{Figures}
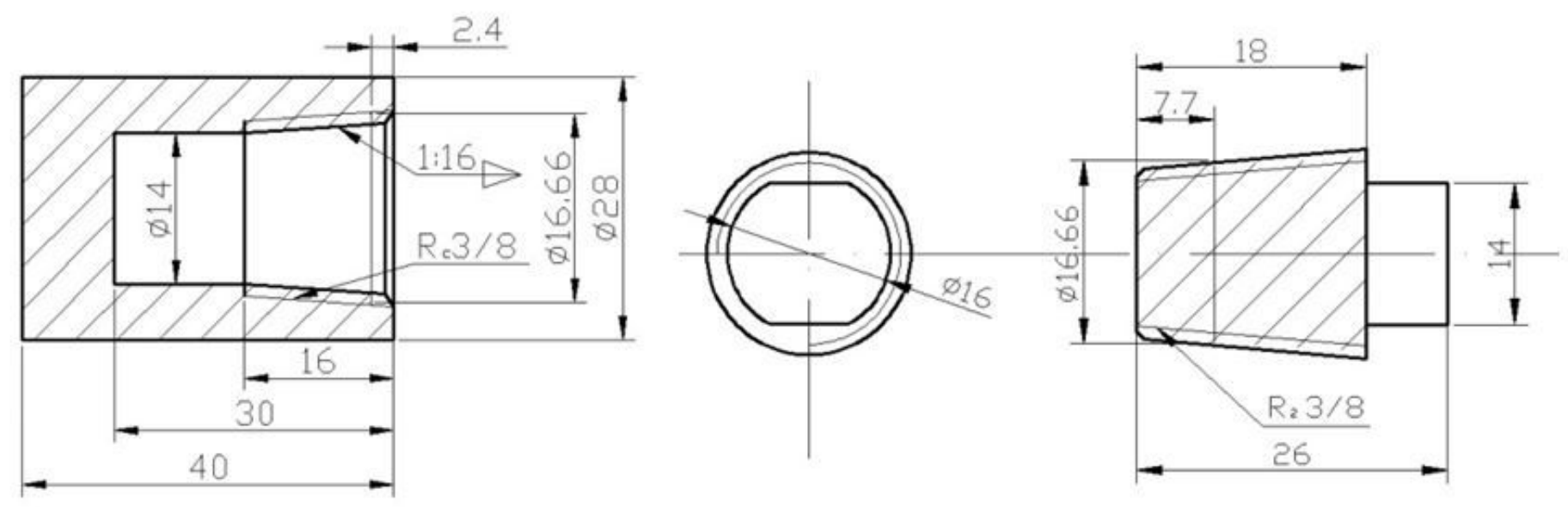

Figure 1

Schematic of the barrel-shaped cylinder and the screw plug.
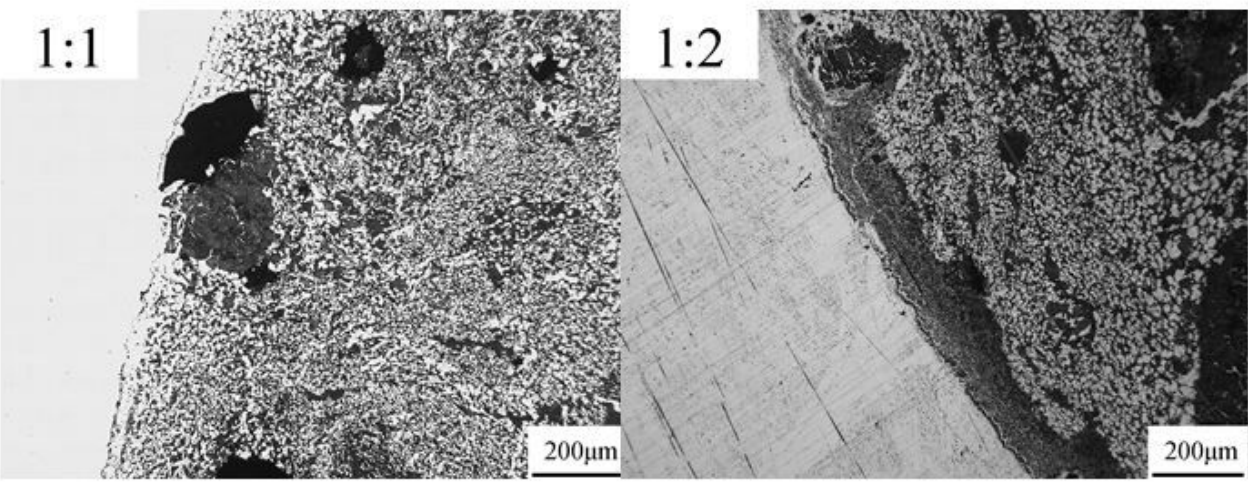

$1: 3$

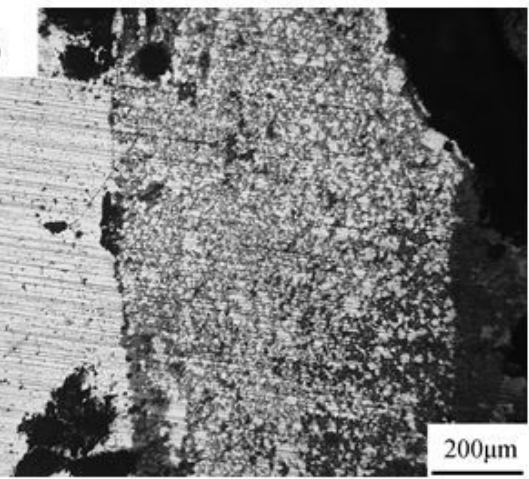

(a)
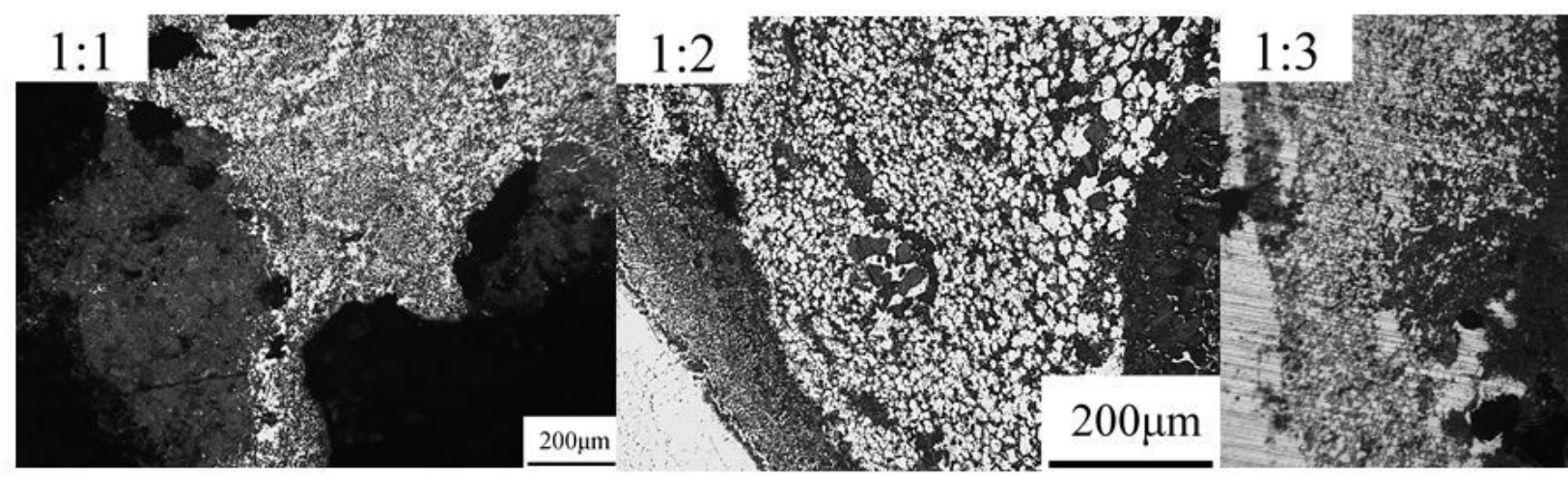

(b)

\section{Figure 2}

Metallographic pictures of atoms at different atomic ratio, (a) Pictures of the cylinder block's neighboring area, (b) Pictures around its core area. 


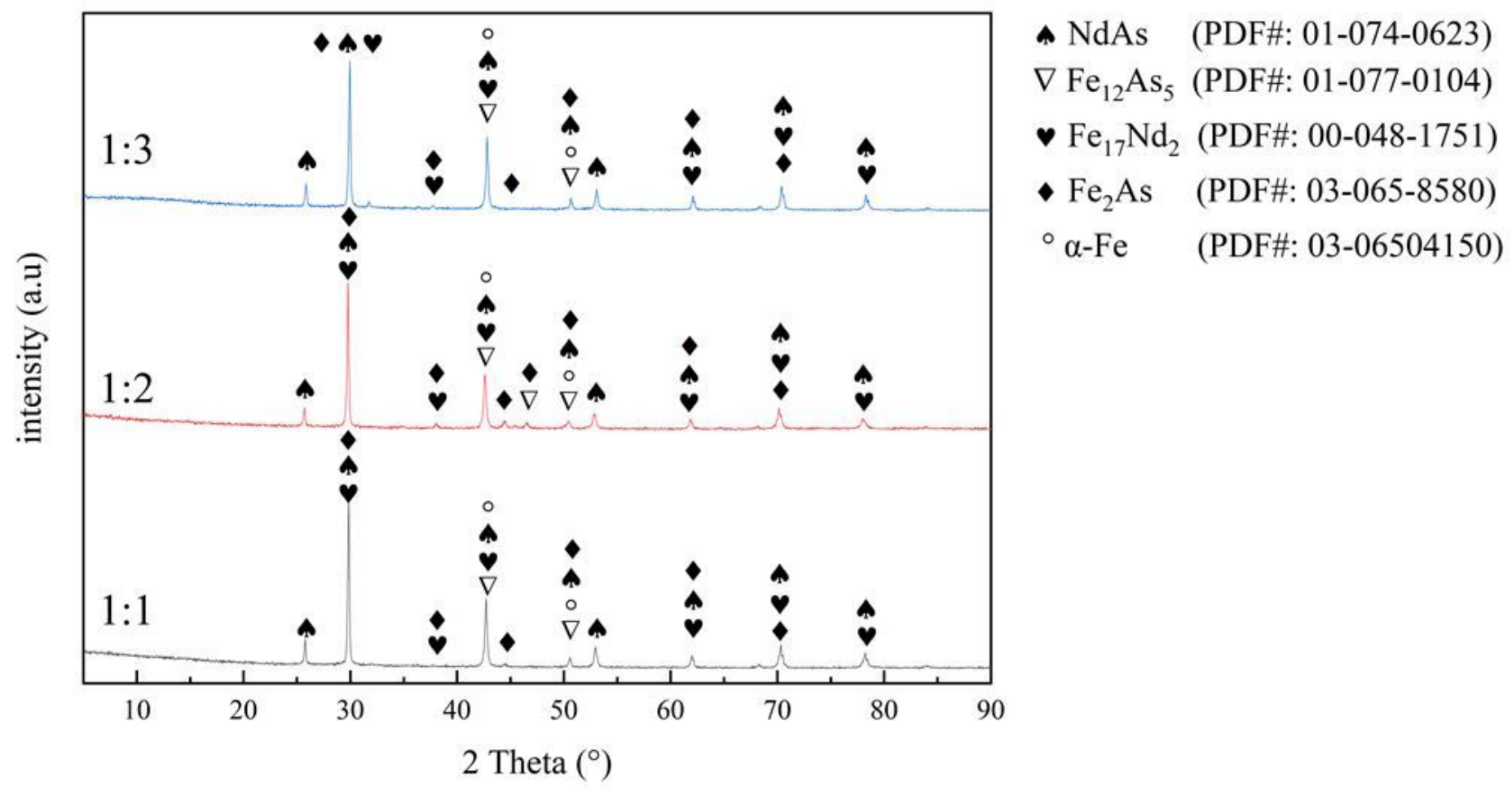

Figure 3

X-ray diffraction spectra of the samples at different atomic ratio.

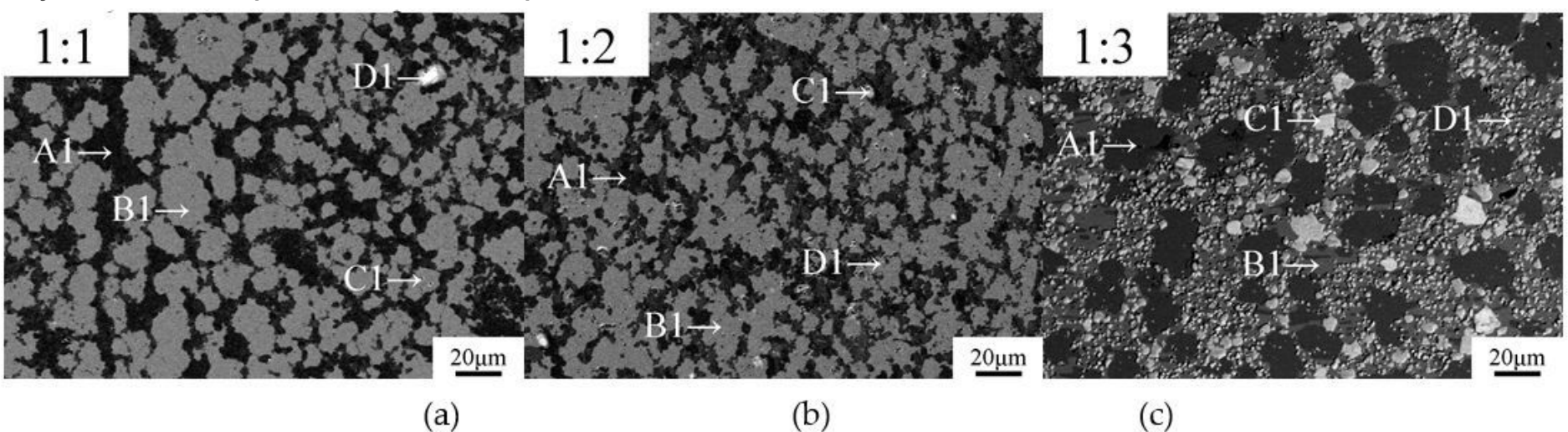

Figure 4

Backscattered electron maps of the sample at various atomic ratios (a) 1:1, (b) 1:2, (c) 1:3. 


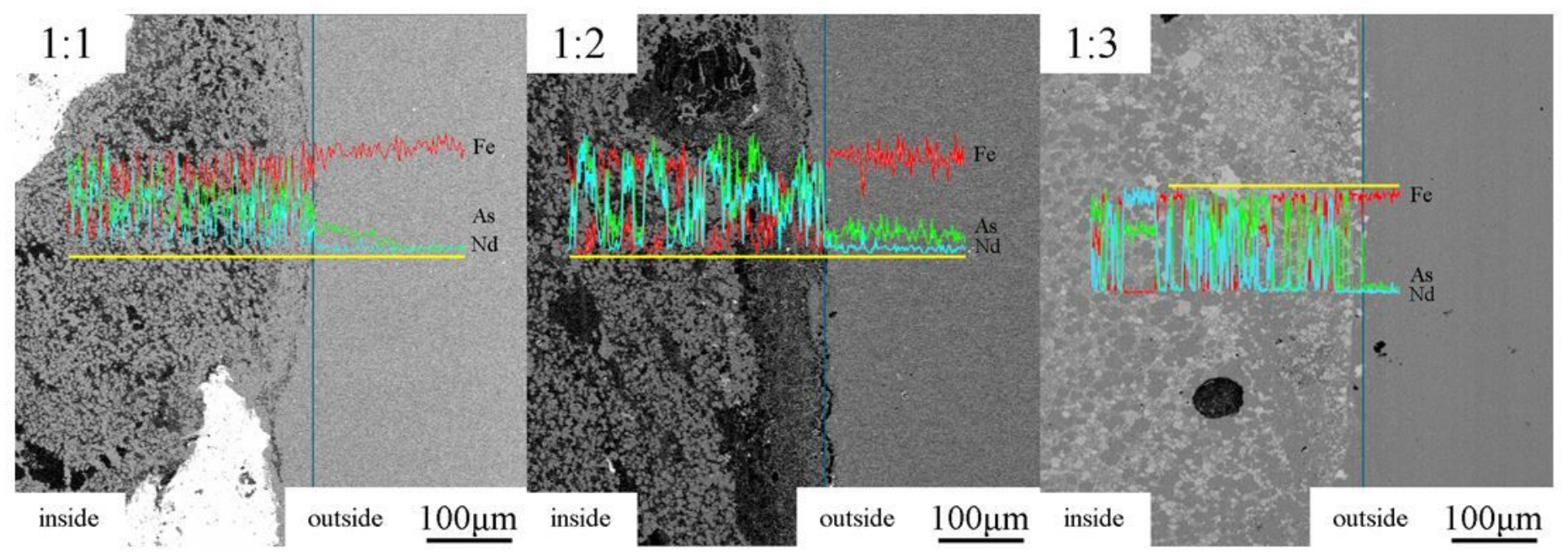

Figure 5

Sweep spectrum of the edge line of the cylinder samples at different atomic ratio.

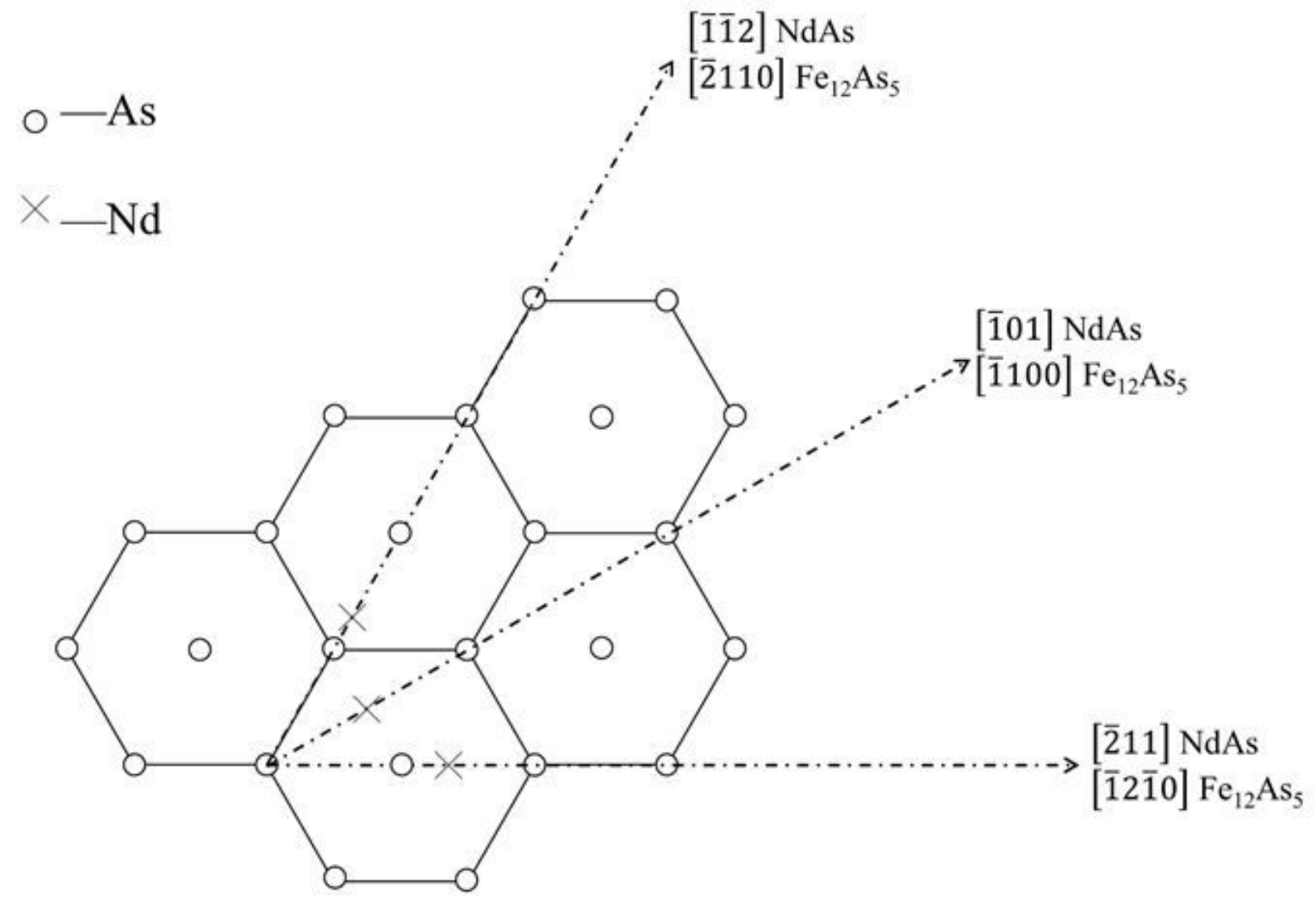

Figure 6

Crystallographic relationships of the Fe12As5 (0001) and NdAs (111) planes. 


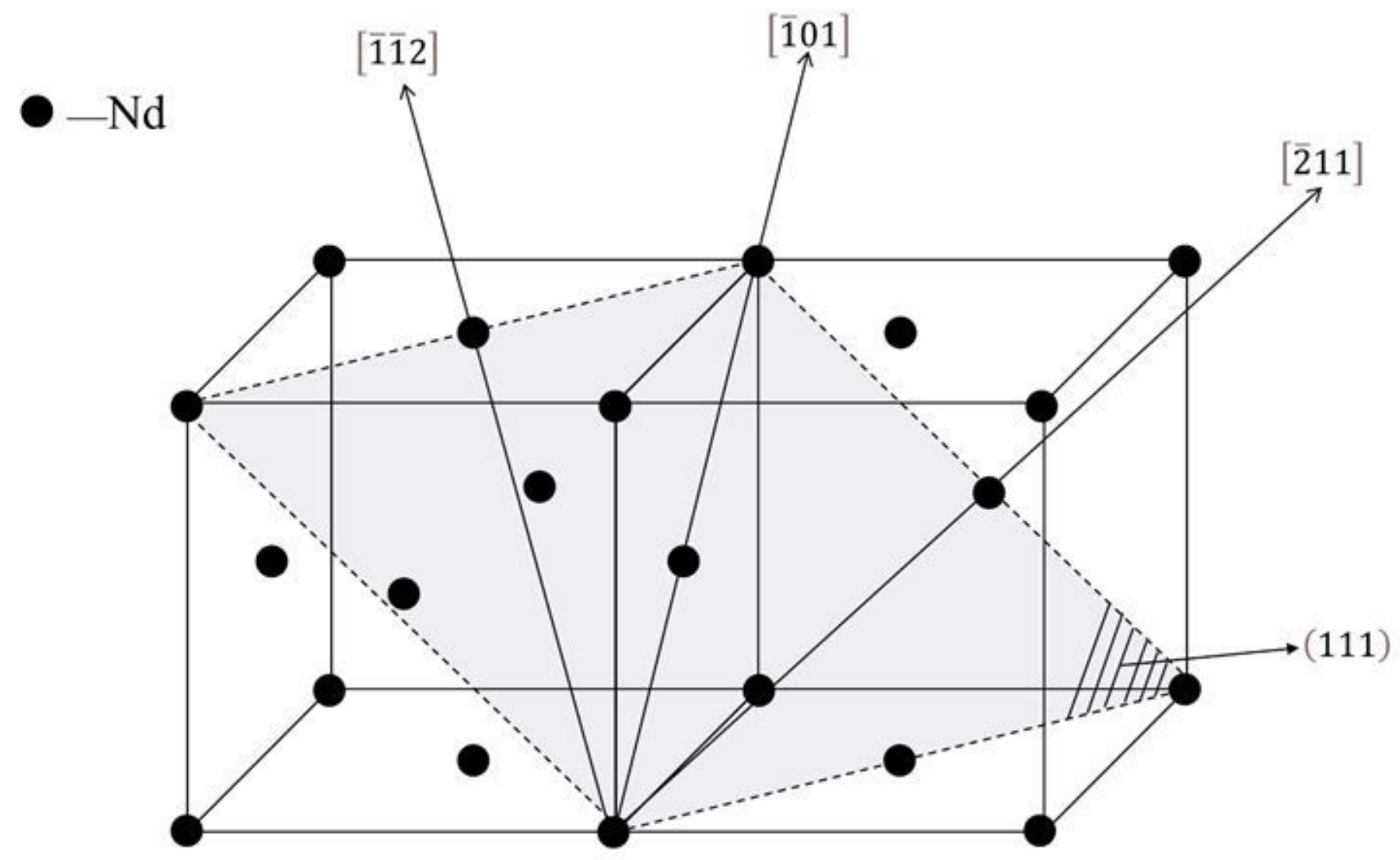

Figure 7

Diagram of plane and crystal direction of NdAs (111). 